\title{
Co-history-matching; a way forward for estimating representative saturation functions
}

\author{
Pedram Mahzari ${ }^{1,2}$, Ali AlMesmari ${ }^{1}$, Mehran Sohrabi $^{1}$ \\ 1 Centre for Enhanced Oil Recovery and CO2 Solutions, Heriot Watt University, \\ 2 Department of Earth Sciences, University College London.
}

\begin{abstract}
Core-scale experiments and analyses would often lead to estimation of saturation functions (relative permeability and capillary pressure). However, despite previous attempts on developing analytical and numerical methods, the estimated flow functions may not be representative of coreflood experiments when it comes to predicting similar experiments due to non-uniqueness issues of inverse problems.

In this work, a novel approach was developed for estimation of relative permeability and capillary pressure simultaneously using the results of "multiple" corefloods together, which is called "co-history-matching". To examine this methodology, a synthetic (numerical) model was considered using core properties obtained from pore network model. The outcome was satisfactorily similar to original saturation functions. Also, two real coreflood experiments were performed where water at high and low rates were injected under reservoir conditions (live fluid systems) using a carbonate reservoir core. The results indicated that the profiles of oil recovery and differential pressure $(\mathrm{dP})$ would be significantly affected by injection rate scenarios in non-water wet systems. The outcome of co-history-matching could indicate that, one set of relative permeability and capillary pressure curves can reproduce the experimental data for all corefloods.
\end{abstract}

\section{Introduction}

Measurement of saturation functions (capillary pressure and relative permeability) is difficult and costly. Relative permeability is dynamic parameter whereas capillary pressure can be categorized as a static function (Taber 1969). Relative permeability can be directly measured by establishing a steady state saturation distribution in the porous media (Morse et al. 1947). However, from a relatively less cumbersome approach, experimental data obtained from unsteady state type of experiments can be used in estimation of relative permeability using semi-analytical and automatic history matching methods [(Johnson et al 1959) and (Chavant et al. 1980)]. However, when the core tests are performed at relatively low rates, inclusion of capillary pressure data can impact the results of relative permeability estimation. Conventionally, capillary pressure is obtained from separate experiments where a different core plug is usually considered. Also, using reservoir cores to be aged with crude oils, establishment of identical initial saturations and wettability would not be a straightforward task. These two factors would often lead to uncertainties in determination of relative permeability where capillary pressure plays a role [(Subbey et al. 2006) and (Honarpour and Mahmoud 1988)]. Furthermore, measurement of capillary pressure at static modes may not represent capillary pressure acting dynamically (in displacements) against the viscous force to trap the nonwetting phase (Weitz et al. 1987).

Automatic history matching has been used numerously as the academic and oil industry standard [(Kumar et al. 2014), (Shafer 2013), and (Eydinov et al. 2007)]. Also, various software applications have been developed to estimate relative permeability and capillary pressure from core tests (Lenormand et al. 2016). However, these attempts and improvements have been focused on numerical simulation of single core experiments, which can be subject multiple sources of errors (Subbey et al. 2006). One approach is to obtain capillary pressure from static 
type of measurements such as porous plate or centrifuge and then incorporate the Pc data into history matching process. This procedure may improve the accuracy of tuned relative permeability curves. On the other hand, it should be pointed out that capillary pressure measurements are time consuming and (compared to coreflood experiments) they may not possess identical initial wettability conditions in non-water wet systems.

Several attempts have been made to simultaneously estimate capillary pressure and relative permeability functions from core tests [(Chavant et al. 1980), (Chardaire-Riviere et al. 1992), (Schembre et al. 2006), (Pini and Benson 2013), and (Basbug and Karpyn 2008)]. However, non-uniqueness issue in the history matching process may introduce uncertainties to some extents. Moreover, obtaining both saturation functions would often require additional information such as in-situ saturation monitoring, which may not be always available for coreflood experiments under reservoir conditions. For systems likely to become mixed to oil wet, hold-ups of oil in the rock due to capillary pressure can be significant and hence, laboratory parameters such as injection rate and core dimensions may impact the outcome of the experiments but, saturation functions should be independent of laboratory procedures. Therefore, it is desired to be able to estimate $k r$ and $P c$ simultaneously from unsteady state core tests due to less cumbersome characteristics of unsteady state experiments. Therefore, despite of numerous attempts to develop methodologies for reliable and predictive $k r$ and $P c$, there is still a need to tailor experimental and simulation approaches to attain a set of saturation function for non-water wet oil/brine systems under reservoir conditions.

In this study, a new principle has been brought into application in which saturation functions $(k r$ and $P c)$ can be consistently estimated from "multiple corefloods" in which a variety of ratios for viscous to capillary forces are considered in "one" history matching technique. Using rock and fluids at reservoir conditions (i.e. non-water wet and live system), it is proposed to perform a number of corefloods (at least two) under different injection rate scenarios. Subsequently, using our proposed history matching technique (explained in next section), one set of saturation functions can be estimated to satisfactorily match multiple corefloods together. This technique is called co-history-matching.

Simulations and history matching of multiple coreflood experiments have been proposed previously for threephase flow to estimate hysteresis parameters [(Duchenne et al 2016), (Mahzari \& Sohrabi 2017a), and Duchenne et al. 2015)]. For water-alternating-gas (WAG) experiments, multiple coreflood history matching could improve the estimation of hysteresis parameters [(Duchenne et al 2016), (Mahzari \& Sohrabi 2017b), and (Mahzari \& Sohrabi 2017a)]. However, the use of multiple coreflood history matching for two phase flow and estimation of $k r$ and $P c$, which are more representative than single coreflood history matching, are discussed in this paper for the first time. Also, the methodologies for setting up a commercial simulator for multiple coreflood history matching is presented in this paper for the first time.

To examine viability of this technique, firstly, a synthetic core model was generated numerically using pore network modeling, which enabled us to have consistent capillary pressure and relative permeability functions based on known pore-throat and known wettability conditions of a rock and fluid system. The saturation functions extracted from pore-network modelling were used to produce coreflood data at different injection scenarios, which are considered as synthetic experimental data. Having consolidated our technique using synthetic data, a series of coreflood experiments was performed under reservoir conditions using live oil and non-water wet (aged) system. Since the system under study can exhibit a non-water wet behavior, injection rate would affect the displacement efficiency. Coreflood experiments at low and high rates were followed by a series of bump flood periods (i.e. 
injection with very high rates), which could lead to production of the oil trapped due to capillary pressure discontinuity such as end effects. Non-water wet systems would possess a relatively significant negative capillary pressure in high water saturation range, which can affect the frontal advancement and also, end-effects. Therefore, inclusion of capillary pressure would become more important in non-water wet systems.

\section{Co-history-matching technique for multiple corefloods}

At laboratory scales, estimation of relative permeability can be affected by capillary pressure and significance of capillary pressure would depend on injection rate scenarios (Civan and Donaldson 1989). At low rate of injection, the capillary forces would dominate whereas in higher flow rates, the capillary forces would be surpassed with the viscous forces depending on wettability and length of the samples. Conventionally, at the end of waterflooding sequence of the tests, a series of high flow rate injections (bump flood) would be suggested to produce the trapped oil by capillary end-effects [(Hinkely and Davis 1986), (Masalmeh 2013), and (Masalmeh 2002)]. The characteristics of bump flood results would have a direct link with magnitude of capillary pressure. Therefore, the relative significance of capillary and viscous forces would play a substantial role on the displacement efficiency, which is mainly expressed by saturation functions (i.e. $k r$ and $P c$ ).

To capture the impact of viscous and capillary forces, a series of core-scale experiments is needed to be performed at different injection rate scenarios. Having performed multiple coreflood experiments at different rates, all experiments can be history matched together to obtain "one" set of saturation functions. Different coreflood experiments are started with low and high rates followed by bump floods to reach to residual oil saturation irrespective of starting rates. This approach can be employed to evaluate the relative strength of viscous and capillary forces. Subsequently, one history matching run is performed for all corefloods to match the experiments together.

For multiple coreflood history matching or (as called here) co-history-matching, a sector model with three layers (for two corefloods) of grid blocks was considered; top layer represents the coreflood performed with low rate, middle layer is null blocks, and bottom layer is for the high rate coreflood experiment. For this methodology, any commercial simulator can be used. Figure 1 illustrates the reservoir model designed for multiple coreflood history-matching. Each active layer (coreflood) can have its own wells perforated at the outlet and inlet grid blocks as producer and injector, respectively. Experimental information obtained from each coreflood can be input for producer and injector of each layer separately. The null layer is considered to ensure zero communications between the main layers representing different corefloods. With this arrangement, it would be doable to run the simulation (all three layers) with a single set of saturation functions while production and injection information are analyzed (matched) separately. Each layer (coreflood) is a one-dimensional model that is analyzed separately however, all corefloods use one set of $k r$ and $P c$. An optimizer is coupled with the simulator (which runs the sector model) to tune the saturation function for matching the experimental data of all corefloods (coreflood=layer) together. This type of history matching can only be used for the experiments performed on identical systems (with same core and fluid systems) where aging process could establish consistent wettability states in the experiments. It should be noted that, this technique can be utilized for more than 2 corefloods, if same principle active-null layers for each coreflood is employed. 
Objective function of each coreflood ${ }_{i}=w_{i} \sum\left(d P_{\text {exp }}-d P_{\text {sim }}\right)_{i}^{2}+w_{i}^{\prime} \sum\left(\text { Oil Vol }_{\text {exp }}-\text { Oil Vol }_{\text {sim }}\right)_{i}^{2}$

Where global objective function is used by the optimizer to be minimized for all coreflood experiments together. Weight factors for each test, each data set ( $d P$ and oil recovery), and each data point can be adjusted to obtain the optimized solution. For data points recorded during experiment, the oil recovery and $d P$ profiles after water breakthrough are assigned with higher weight factors compared to before breakthrough. It is accepted that in unsteady state experiments, the experimental information after breakthrough can only be used for history matching. In Figure 1, oil volume and $d P$ recorded from experiment (layer) "1" are used as matching data for OilVol and $d P\left(d P=\mathrm{P}_{\text {Injector-1 }}\right.$ minus $\left.\mathrm{P}_{\text {Producer-1 }}\right)$ in equation 2. This procedure would be followed for other corefloods as well and then, one global objective functions is used for all corefloods. Although different data points are to be matched (for different corefloods), "one" set of relative permeability and capillary pressure is used as input for all corefloods to obtain the history-matching.

For setting up the simulation in this study, one-dimensional numerical simulation was constructed for each layer with 100 grid blocks using a black oil simulator (CMG package). Using CMG-CMOST with its CMG Designed Exploration and Controlled Evolution (CMG's proprietary algorithm) for minimization of objective functions (this is an improved genetic algorithm), reservoir simulator was coupled with the optimizer to estimate $k r$ and $P c$ simultaneously. This optimization algorithm is based on estimation of posterior probability function of a parameter, which is expressed by the following equations:

$$
\begin{gathered}
p(x)=\frac{P_{o}(x) L(x)}{\sum P_{o}(x) L(x)} \\
L(x)=e^{-Q(x)}
\end{gathered}
$$

Where $p(x)$ is the posterior probability function, $P o(x)$ is the prior probability function, and $L(x)$ is the likelihood function using $Q(x)$ as the objective function. The basis of this optimization method is the Bayesian type of minimization (Akbarabadi et al. 2015). For incorporating capillary end-effects, as can be seen in Figure 1, two grid blocks at the outlet were assigned with zero capillary pressure, i.e. 98 grid blocks with adjustable nonzero capillary pressure and two grids with zero Pc. For relative permeability and capillary pressure functions, LET formulations were incorporated to have flexible correlations [(Lomeland et al. 2005) and (Lomeland and Ebeltoft 2008)]. In the history matching process, the minimization algorithm was continued until a cumulative error of less than $0.01 \%$ is achieved. The cumulative error is defined as the sum of error of cumulative oil production and differential pressure profiles. The boundary conditions (i.e. inlet and outlet conditions) are imposed to mimic the experimental conditions. When reservoir simulators (e.g. CMG) are used, the issue is that, the well specifications (boundary conditions) such as perforations and completion may not be applicable to core-scale parameters. However, in simulations performed here, the well index (controlling inlet and outlet conditions) are calculated by slim-tube type of well index (imbedded in CMG), which resembles core-scale boundary conditions as employed in Sendra (which is a core-scale simulator). In the Figure 14 and 15, the results of CMG and Sendra were compared to show the consistency in imposing the boundary conditions.

To verify the proposed experimental procedure and history matching technique, firstly, a synthetic model was developed using digital rock data and co-history-matching technique was employed to back-calculate the saturation functions. Secondly, after a detail analysis of synthetic model, two real coreflood experiments were 
performed under reservoir conditions using live fluids and non-water wet system to examine applicability of the co-history-matching for realistic cases.

\section{Synthetic model}

Pore network modeling has been considered as a feasible tool for simulating pore-scale processes in multiphase flow [(Blunt et al. 2013), (van Dijke and Sorbie 2002), and (Oren et al. 1998)], which can generate rock properties for single phase and multiphase flow. Using arbitrary $k r$ and $P c$ for synthetic models would not lead to consistent representation of a rock because numerous parameters would be interdependent. However, the main advantage of pore network models is the consistency in the generated parameters. Therefore, saturation functions generated from a pore network model would be self-consistent. Also, the synthetic model can possess any wettability state by selecting a range of contact angles that are related to particular wettability regime (Valvatne et al. 2005). In this work, a synthetic model is constructed using available information of an extracted pore network of a sandstone rock. After that, the self-consistent rock properties generated by pore network modelling would be scaled up to core-scale sizes and then, three waterflood experiments would be numerically performed using CMG simulator. The saturation functions obtained from pore-scale modeling would be named as numerical experimental data. Using co-history matching technique, two numerical coreflood experiments would be history matched together. Also, two separate history matching exercises would be carried out on single coreflood experiments separately to compare the outcomes of single coreflood history matching against co-history-matching. After that, different saturation functions obtained from single coreflood and multiple corefloods history matching were used to predict another waterflood at a different rate to compare predictive capability of co-history-matching technique.

Synthetic model properties. Pore and throat size data of a sandstone rock (Sandstone-S5) has been extracted and digitized by pore-scale modelling group in Imperial College University (Dong and Blunt 2009). Figure 2 depicts micro-scale image of rock thin section and also, extracted pore and throat size distributions of the network. Porosity and permeability of the model is 0.211 and $4638 \mathrm{mD}$, respectively. To initialize the model, contact angle distribution of 80-120 degree with random distribution was selected, which would represent mixed wet conditions [(Blunt 1997) and (Kovscek et al. 1993)]. To generate two-phase saturation functions, i.e. $k r$ and $P c$, a software for pore-scale two-phase flow developed by the same group (Valvatne et al 2005) was used to perform an imbibition process, which would represent water injection. The software has been developed based on quasi-static invasion for two-phase flow.

Figure 3 shows the saturation functions generated with pore-scale modeling. Critical water saturation and residual oil saturation are 0.21 and 0.06 , respectively. Since the relative permeability data points are not smooth, LET parameters were tuned to construct the curves on the relative permeability data points. Smoothness of relative permeability curves facilitates running the coreflood simulations. Having obtained a set of smoothed $k r$ and $P c$ functions, the curves were input into the coreflood simulator to generate oil production and $d P$ (differential pressure) data. The numerical corefloods were performed with starting injection rates of 5 and $60 \frac{\mathrm{cm}^{3}}{\mathrm{hr}}$ for low and high rate numerical experiments. The bump flood periods for low rate test were sequentially performed at rate of 20,50 , and $100 \frac{\mathrm{cm}^{3}}{\mathrm{hr}}$. For high rate case, the bump flood was $200 \frac{\mathrm{cm}^{3}}{\mathrm{hr}}$. The selection of rates for synthetic model is based on the real coreflood experiments (to be discussed in next section) to keep consistency. Likewise, fluid viscosities and core dimensions were kept identical between synthetic and real cases. The injection rates selected 
for this study is equivalent to $1.5 \frac{\mathrm{ft}}{\mathrm{day}}$ and $18 \frac{\mathrm{ft}}{\mathrm{day}}$ of advancement velocity. In these flow ranges, capillary number would not be changed significantly to affect the residual non-wetting phase saturations. On the other hand, the rates selected would enable analysing the competition between viscous and capillary forces (when $k r$ and $P c$ are still unaffected by injection rate) in laboratory scales. If the injection rate was increased in much higher degrees, there could be a possibility to enter regions where $k r$ and $P c$ could be affected by injection rate based on capillary number and desaturation curves (Taber 1969). Therefore, the low rate was selected at nominal reservoir rates and the high rate was chosen to stay in stable zone of desaturation curve. It should be pointed out that, the methodology proposed and developed here can be employed for laboratory experiments to obtain representative saturation function, which then can be used for field simulations.

Figure 4 shows the results of numerical coreflood experiments. As can be seen, for the low rate case (Fig 4b), significant oil recovery was obtained when the bump flood period started, which indicates mixed wettability of the core and hence, considerable oil trapping at the end of the core. On the other hand, for high rate case (Fig 4a), increasing the injection rate could lead to marginal additional oil recovery. The difference in the behavior of bump floods in low and high rates can be linked to the magnitude of $d P$ compared to $P c ; d P$ of low rate at the end of main injection period is 0.05 psi whereas, $d P$ of high rate is 0.22 . In other words, $d P$ of 0.05 psi would correspond to significant holdup of oil based on $P c$ curve in Fig $3 \mathrm{~b}$. To analyze the impact of bump flood periods, saturation profiles along the core can be plotted to check if high injection rate would surpass the end effects. Figure 5 illustrates the water saturation profiles along the core after breakthrough and after bump floods, which indicates uniform water saturation distribution after bump floods.

\section{Analyses of different history matching approaches}

History matching using single coreflood. Conventionally, relative permeability functions would be estimated using coreflood data of a single experiment. If capillary pressure data is available, it would be used as a fixed parameter during history matching. Although $J B N$ (Johnson et al. 1959) as a semi-analytical can be used to verify numerical simulations, analytical approaches would not be a good option for non-water wet systems where capillary pressure can play a crucial role. Therefore, history matching needs to be used for non-water wet systems. However, measurement of capillary pressure curves for non-water wet systems under reservoir conditions is cumbersome and costly. Nevertheless, in this section, this conventional approach would be examined and single corefloods would be history matched separately to highlight the advantages of co-history-matching. The estimated saturation functions (from a single coreflood) would be used for prediction of the other coreflood. It should be mentioned that, in history matching process, capillary pressure curves were allowed to change slightly (5\% variation band in Pc values), which is a fair assumption if the errors of laboratory measurements are considered. First, the low rate numerical experiment ( $k r$ and $P c$ obtained from pore-network modeling) was history matched and the other numerical test (high rate) was predicted. Figure 6 illustrates the results of history matching of the low rate numerical experiment (Fig 6a) along with forward simulation (prediction) of high rate case (Fig 6b). Using saturation functions obtained from low rate has resulted in noticeable error in simulation of both oil recovery and differential pressure profiles. Second, when the high rate numerical experiment was history matched, the prediction of low rate case was again erroneous, as shown in Figure 7. This discrepancy between the outcome of 
history matching and forward simulation of similar experiments can be attributed to non-uniqueness nature of history matching process.

In other words, there may be a solution that can match one experiment with reasonable accuracies but, due to nonuniqueness problem, the history matching attempt could not converge to the consistent solution. Therefore, there is a need to develop a methodology that can constraint the history matching process for the consistent solution. For this purpose, instead of statistical analysis and uncertainty concepts, another technique was considered, i.e. co-history-matching, which is based on physical interpretations of viscous and capillary forces.

Co-history-matching to obtain saturation functions. Having identified that history matching of single coreflood can be erroneous and heavily affected by non-uniqueness issues, co-history-matching technique was employed using a sector model with three layers. Same optimization algorithm was incorporated with aid of CMG-CMOST software. Figure 8 demonstrates the results of co-history-matching of two corefloods together. Relative permeability and capillary curves were tuned simultaneously to match both numerical experiments. The error of history matching was $0.01 \%$, which indicates an acceptable accuracy. One may argue that using the co-historymatching technique with a sector model can bring about high computation run time for simulation and history matching processes. Based on the outcome of co-history-matching performed on synthetic model, the run time for a sector model is relatively higher than that of single 1-D coreflood simulation, i.e. 2 days for co-historymatching versus 4 hours for single coreflood. Therefore, the time scale of history matching of multiple corefloods is overall insignificant.

The main advantage of using synthetic model is the fact that the tuned relative permeability and capillary pressure curves can be compared against the known values (information generated by pore network modeling). Figure 9 illustrates the tuned relative permeability and capillary pressure curves estimated from co-historymatching and single coreflood approaches. It should be pointed out that, for unsteady state waterfloods, the estimated $k r$ and $P c$ would be more reliable in the saturation ranges pertinent to after water breakthrough, which can be considered for comparison of $k r$ and $P c$ curves. As can be seen from Fig9a, the estimated relative permeability curves from co-history-matching technique is satisfactorily similar to the experimental $k r$ (pore network $k r s$ ). Also, for capillary pressure (Fig9b), our proposed methodology could lead to an acceptable similarity between co-history-matching and experimental data. On the other hand, the comparison between single coreflood history matching and experimental data has indicated discrepancies. It should be mentioned that, for single coreflood history matching, Pc curves were allowed to be changed by $5 \%$ (from experimental data) to show the discrepancies even though Pc was constraint to be close to experimental data. But for co-history-matching, tuning of Pc was converged with high flexibility in Pc variation. Therefore, the history matching of single coreflood replicate a practice where Pc had been measured by a separate test with an acceptable error of measurement (i.e. 5\%). It can be noticed that, even for co-history-matching, the estimated $k r$ and $P c$ could not reasonably match experimental data in saturation ranges before breakthrough, i.e. water saturation of 0.0-0.4. Therefore, the tuned $k r$ and $P c$ are reliable for after breakthrough saturation ranges.

To examine the predictive capability of the different history matching approaches, another coreflood experiment was numerically performed under a different injection rate (i.e. $10 \frac{\mathrm{cm}^{3}}{\mathrm{hr}}$ ). Figure 10 exhibits the results of simulations using different set of saturation functions obtained from history matching ( $k r$ and $P c$ pairs of Figure 9), which are compared with experimental data. Evidently, the outcome of simulation using co-history-matched 
$k r$ and $P c$ has indicated an acceptable similarity with experimental data. On the other hand, the estimated saturation functions from single coreflood test has failed to predict the numerical experiment with adequate accuracies. Therefore, using synthetic model with consistent $k r$ and $P c$ functions, the advantages of co-history-matching over single corefloods could evidently lead to estimating saturation functions with acceptable predictive capabilities. It should be mentioned that co-history-matching technique has been developed to alleviate the non-uniqueness issue, which could adversely affect single coreflood history matching.

\section{Co-history-matching of corefloods under reservoir conditions}

Although the co-history-matching technique could be employed and successfully tune saturation functions for synthetic model, there is a need to evaluate the application of this technique on real coreflood experiments. Two coreflood experiments were performed under reservoir conditions using carbonate rocks and live oil. The experiments were designed in a way to represent real reservoir fluids and rock where the system is aged to achieve non-water wet states. Co-history-matching technique was employed to obtain $k r$ and $P c$ simultaneously. It should be noted that for these coreflood experiments with live oil and non-water wet system, obtaining experimental $k r$ and $P c$ directly by another experiment is extremely cumbersome and prone to laboratory errors. Also, static capillary pressure curves conventionally obtained from centrifuge of porous disc methods may not be representative of dynamic Pc acting in mixed wet systems (Hassanizadeh et al. 2002). Thus, the estimated relative permeability and capillary pressure curves would be accounted as most representative solution of the system, which has been verified by the analyses performed on the synthetic model. The main objective of the experiments is to demonstrate that this approach can be applied for real cases.

Real laboratory experiment may inherit a degree of uncertainty arising from observation and readings of data, which could not be relevant to numerical experiments. In numerical experiments, on the other hand, a number of parameters would be lumped into formulations and equations. Although the numerical saturation functions could be supported by concepts of digital rock physics, there can be uncertainties related to boundary conditions and 3D heterogeneity of real corefloods that could not be captured in numerical corefloods. Therefore, here in this work, the numerical corefloods were only used to demonstrate that the methodology of co-history-matching can be employed for multiple corefloods performed carefully irrespective of intrinsic experimental errors.

Rock and fluid properties. A composite carbonate core formed with five core plugs was used in this study. Flexible filter papers infused with rock powder were placed between the plugs to reduce the impact of core discontinuity. The average brine permeability and porosity of the core can be found in Table 1 . The composition of injection brine is shown on Table 2. Live oil was made using dead crude oil pre-equilibrated with a fourcomponent gas $(\mathrm{C} 1-\mathrm{C} 4)$. Details of fluid and rock properties can be found in (Mahzari et al 2018). The aqueous phase was pre-equilibrated with the solution gas to minimize the mass transfer between the invading brine and the resident oil, which may strip the oil from light components as water contacts with resident oil. This mass transfer may change the saturation of resident oil due to in-situ swelling or shrinkage of oil phase. Properties of live fluids can be found in Table 3 .

Experimental setup and procedure. The experimental setup used for the experiments is shown schematically in Figure 11. The pressure at the core outlet (back pressure) was kept constant at 3100 psi in all experiments and the 
core flood experiments were performed under constant temperature at $100{ }^{\circ} \mathrm{C}$. Carbonate cores were first cleaned, dried and then irreducible water saturation $(\mathrm{Swi})$ was established. The core was first saturated with dead oil and was allowed to age (while injecting crude oil with rate of $1.5 \frac{\text { Pore Volume }}{\text { week }}$ ) for three weeks. Recombined live oil was then injected into the core to displace the dead crude oil. The injection of live oil was continued through the core for three pore volumes until the recorded gas content reached the initial value, i.e. $R_{s}$.

Having finished the first waterflood (i.e. low rate followed by bump floods), the core was cleaned using sequential injection of toluene and methanol. The cleaning process was performed under $110{ }^{\circ} \mathrm{C}(10$ degree above test temperature) and 1000 psi. After cleaning, the core permeability was measured using formation water, which was 96.51 $\mathrm{mD}$. After that, Swi was established following same procedure and Swi of 0.16 was achieved. The core was aged for three weeks again. It should be noted that, at end of aging, the oil relative permeability at Swi(kro@ Swi) for both experiments was established similarly, i.e. 0.61 for the first test and 0.58 for the second test. The similarities in initial conditions in both experiments can enable performing co-history-matching. The details of experimental procedure for waterfloods can be found in (Mahzari et al. 2017c).

Results of experiments. In the first test, live water was injected through the core with a rate of $5 \frac{\mathrm{cm}^{3}}{\mathrm{hr}}$ equivalent to flow velocity of $1.5 \frac{f t}{d a y}$ whereas in the second experiment, at the high rate experiment, water injection was performed with a rate of $60 \frac{\mathrm{cm}^{3}}{\mathrm{hr}}$ that corresponds to the flow velocity of $18 \frac{\mathrm{ft}}{\mathrm{day}}$. At the end of low rate water injection, a sequence of bump flood was performed in ascending rates to recover the oil trapped as the result of end-effects. From original injection rate of $5 \frac{\mathrm{cm}^{3}}{\mathrm{hr}}$, the rate was increased to 20 and 50 and $100 \frac{\mathrm{cm}^{3}}{\mathrm{hr}}$ sequentially. The entire bump flood period was performed for $1 \mathrm{PV}$ and hence, the oil recovered during bump flood can be mainly attributed to the oil trapped due to capillary hold-ups.

Figure 12 shows the oil recovery profile $(\% O O I P)$ and the differential pressure $(d P)$ obtained during the water injection for both tests. For low rate experiment, the breakthrough of the injection water happened at 0.21 pore volume injected as detected by appearance of water in effluent and drop in $d P$. The ultimate recovery of $36.1 \%$ was obtained during low rate injection, which was followed by $4 \%$ additional oil recovery during the bump flood. Once the bump flood finished, the rate was reduced to original value of $5 \frac{\mathrm{cm}^{3}}{\mathrm{hr}}$, which resulted in zero oil flow. For high rate experiment, similar to the first experiment, a cycle of bump flood was performed after waterflood to establish the residual oil saturation across the core. One advantage of the experimental results was the relatively wide range of saturations obtained after breakthrough, which makes the estimated $k r$ and $P c$ more reliable with respect to wide water saturation.

Figure 13 illustrate the oil recovery profiles during water injection to highlight the impact of injection rate on the oil displacement. As can be seen, the low injection rate plus its corresponding bump floods would produce residual oil saturation compared to high rate cases. The breakthrough happened in the comparably same pore volume injected, which indicates the resident oil was displaced similarly in two cases. The similarity between the low rate plus bump flood with the high rate indicates that, the difference between low and high rate is mainly due to the end-effects rather than different displacement patterns. In other words, the residual oil saturation away from either ends of the core is similar in both high and low rates. 
Co-history-matching of two corefloods. The coreflood experiments performed at low and high rates followed by bump floods were history matched to estimate relative permeability and capillary pressure. Figure 14 and Figure 15 shows the results of co-history-matching exercise performed as a multiple coreflood history matching, which indicates an acceptable degree of agreement between the experimental data and simulation results. The bump flood part of $d P$ for low rate experiment was history matched but not included in the plot since it would mask the comparison of $d P$ profiles during low rate periods. In this analysis, the results of CMG simulation were compared with Sendra to check if the different formulations of injector and producer would affect the coreflood simulations. Commercial reservoir simulators have been developed for large scales primarily and hence, injection and production wells are perforated in the center of grid block using radial flow formulations, which is not consistent with 1D linear flow of core-scale laboratory experiments. Although CMG has introduced a keyword (SLIMTUBE), which would calculate well index based on linear flow, it is needed to validate the results of CMG with a core-scale simulator, i.e. Sendra.

Figure 16 illustrates the estimated relative permeability and capillary pressure curves obtained through cohistory matching technique. As can be seen, the capillary pressure curves exhibit oil-wet characteristics. The magnitude of capillary pressure was estimated as a low Pc between 0 and 3 psi, which is in agreement with high permeability of the core. As calculated from co-history-matching, the residual oil saturation to waterflood (Sorw) and irreducible water saturation (Swi) are 0.32 and 0.18 , respectively. If the estimated saturation functions $(k r$ and $P c$ ) could predict another coreflood experiment performed using same core and fluids but different ratio of viscous to capillary forces, the tuned saturation functions would be reliable. Displacement tests at different rates were performed which may imply different regimes of viscosity to capillary forces. One of the coreflood experiments was performed at a rate of $5 \frac{\mathrm{cm}^{3}}{\mathrm{hr}}$ whereas the other coreflood was done at $60 \frac{\mathrm{cm}^{3}}{\mathrm{hr}}$ which is one order of magnitude higher. It would be expected to see less impact of capillary forces at higher rates. Although a co-history-matching was performed, this multiple coreflood simulation can be analyzed as a history matching of one coreflood and forward simulation of another coreflood, which can be considered as a predictive exercise. Therefore, the prediction capability of the saturation functions indicates that the tuned water-oil relative permeabilities and capillary pressure can be used as the representative two-phase flow characteristics.

\section{Conclusions}

Co-history-matching can be a new methodology to obtain a set of representative saturation functions that can express two phase displacements in a way that relative significance of capillary and viscous forces can be captured. To demonstrate this method, the synthetic and the real core models were utilized to generate required information for verifying the consistency of co-history-matching. For the synthetic model, pore network modeling was incorporated to generate consistent properties of a digitized rock sample. The design of experiments was purposefully targeted to capture the relative strength of capillary and viscous forces by selecting different injection rate scenarios. The low injection rate experiment could lead to capillary hold up and subsequent bump floods resulted in additional oil recovery, which can show the competitions between the forces, whereas the high rate experiment could express the oil recovery with less impact of capillary pressure. The outcome of co-historymatching technique could successfully estimate a set of $k r$ and $P c$ that resemble experimental data (pore network 
model) and also, the saturation functions could satisfactorily predict another numerical coreflood experiment. Clear advantages of co-history-matching over conventional approaches were observed.

Two real coreflood experiments were performed under reservoir conditions using live fluids and carbonate reservoir cores. As observed from experimental data of low and high rate experiments, at non-water wet conditions, the relative significance of capillary pressure would become critically important in estimation of relative permeability. Based on the experiments, the multiple coreflood history matching was set up to obtain relative permeability and capillary pressure. The outcome of history matching could lead to a single set of saturation functions that can reproduce the experimental data with acceptable degree of similarities. Since coreflood experiments are conventionally designed to study multiphase flow in one core, the methodology proposed in this work can be employed to design the coreflood experiments in a way that relative permeability and capillary pressure can be consistently estimated from multiple experiments. It is worthwhile mentioning that co-history-matching approach can only be employed for core samples initialized comparably using identical core and fluid samples.

\section{Acknowledgement}

We would like to thank Saudi Aramco for technical and financial support provided to this project.

\section{References}

Akbarabadi, M., Borges, M., Jan, A., Pereira, F., Piri, M., “'A Bayesian framework for the validation of models for subsurface flows: synthetic experiments”, Computational Seoscience (2015), 19, 1231-1250.

Basbug, B. and Karpyn, Z., "Determination of relative permeability and capillary pressure curves using an automated history-matching approach", SPE Eastern Regional /AAPG Eastern Section Joint Meeting (2008), 11 15 October, Pittsburgh, USA.

Blunt M. J., "Pore level modeling of the effects of wettability", SPE Journal (1997), 2, 494-510.

Blunt M., Bijeljic B., Dong H., Gharbi O., Iglauer S., Mostaghimi P., Paluszny A., Pentland C., "Pore-scale imaging and modelling”, Advances in Water Resources (2013), 51, 197-216.

Chavant, G., Cohen, G., Espy, M., "Determination of relative permeability and capillary pressure by an automatic adjustment method" SPE Annual Technical Conference and Exhibition, September 1980, SPE 9237.

Chardaire-Riviere, C., Chavent, G., Jaffre, J., Liu, J., Bourbiaux, B. J., "Simultaneous Estimation of Relative Permeabilities and Capillary Pressure” SPE Formation Evaluation, 1992, Vol. 7, 283-289.

Civan F. and Donaldson E. C., "Relative permeability from unsteady-state displacements with capillary pressure included", SPE Formation Evaluation (1989), 4, 189-193.

Dong H., Blunt M. J., "Pore-network extraction from micro-computerized-tomography images", Physical Review E (2009), 80, 036307.

Duchenne, S., de Loubens, R., Petitfrere, M., Joubert, T., "Modeling and simultaneous history-matching of multiple WAG coreflood experiments at reservoir conditions", Abu Dhabi International Petroleum Exhibition and Conference (November 2015), Abu Dhabi, UAE, SPE-177531-MS.

Duchenne, S., de Loubens, R., Joubert, T., "Extended three-phase relative permeability formulation and its application to the history-matching of multiple WAG corefloods under mixed-wet conditions", Abu Dhabi International Petroleum Exhibition and Conference (November 2016), Abu Dhabi, UAE, SPE-183257-MS. 
Eydinov, D., Gao, G., Li, G., Reynolds, A.C., "Simultaneous estimation of relative permeability and porosity/permeability fields by history matching production data", Canadian International Petroleum Conference (June 2007), Calgary, Canada, PETSOC-2007-143.

Hassanizadeh S. M., Celia M. A., Dahle H. K., "Dynamic effect in the capillary pressure-saturation relationship and its impact on unsaturated flow", Vadose Zone Journal (2002), 1, 38-57.

Hinkely, R.E. and Davis, L.A., "Capillary Pressure Discontinuities and End effects in Homogeneous Composite Cores: Effect of Flow Rate and Wettability", SPE Annual Technical Conference and Exhibition (1986), 5-8 October, New Orleans.

Honarpour, M., Mahmoud, S. M., “Relative permeability measurements: an overview” Journal of Petroleum Technology, 1988, Vol. 40, 963-966.

Johnson, E. F., Bossler, D. P., Naumann, V. O., "Calculation of relative permeability from displacement experiments" Trans. AIME, 1959, Vol. 216, 370-372.

Kovscek A. R., Wong H., Radke C. J., “A pore-level scenario for the development of mixed wettability in oil reservoirs", AIChE Journal (1993), 39, 1072-1085.

Kumar, S., Awang, M., Abbas, G., Farouque, K., Ahmed, S., “Simulation protocol for core flooding: relative permeability and capillary pressure analysis", Offshore Technology Conference-Asia (March 2014), Kuala Lumpur, OTC-24715-MS.

Lenormand, R., Lorentzen, K., Maas, J.G., Ruth, D., “Comparison of four numerical simulators for SCAL experiments", International Symposium of the Society of Core Analysts (August 2016), Snowmass, USA, SCA2016-006.

Lomeland, F., Ebeltoft, E., Thomas, W. H., "A new versatile relative permeability correlation" Society of Core Analysts, 2005, SCA2005-32.

Lomeland, F., Ebeltoft, E., “A new versatile capillary pressure correlation.” Society of Core Analysts, 2008, SCA2008-08.

Mahzari, P. and Sohrabi, M., "A robust methodology to simulate water-alternating-gas experiments at different scenarios under near-miscible conditions" SPE Journal (2017a), 22, 1506-1518.

Mahzari, P. and Sohrabi, M., "An improved approach for estimation of flow and hysteresis parameters applicable to WAG experiments" Fuel (2017b), 197, 359-372.

Mahzari, P., Tsolis, P., Sohrabi, M., Enezi, S., Yousef, A. A., Eidan, A. A., “A comprehensive experimental study of pore-scale and core-scale processes during carbonated water injection under reservoir conditions" SPE Kingdom of Saudi Arabia Annual Technical Symposium and Exhibition held in Dammam (2017c), SPE-KSA110 .

Mahzari, P., Tsolis, P., Sohrabi, M., Enezi, S., Yousef, A. A., Eidan, A. A., “Carbonated water injection under reservoir conditions; in-situ WAG-type EOR” Fuel (2018), 217, 285-296.

Masalmeh S. K., "The effect of wettability on saturation functions and impact on carbonate reservoirs in the Middle East", $10^{\text {th }}$ Abu Dhabi International Petroleum Exhibition and Conference (2002), SPE 78515.

Masalmeh, S.K., "Determination of waterflooding residual oil saturation for mixed to oil-wet carbonate reservoir and its impact on EOR", SPE Reservoir Characterization and Simulation Conference and Exhibition (2013), 16-18 September, Abu Dhabi.

Morse, R. A., Terwilliger, P. L., Yuster, S. T., "Relative permeability measurements on small core samples" Producer Monthly, (Aug 1947) Vol. 11, No. 10, pages 19-25. 
Oren P. E., Bakke S., Arntzen O. J., "Extending predictive capabilities to network models", SPE Journal (1998), 3, 324-336.

Pini, R. and Benson S. M., "Simultaneous determination of capillary pressure and relative permeability curves from core-flooding experiments with various fluid pairs", Water Resource Research (2013), 49, 3516-3530.

Schembre J. M. and Kovscek A. R.; "Estimation of dynamic relative permeability and capillary pressure from countercurrent imbibition experiments" Transport in Porous Media (2006), 65, 31-51.

Shafer, J., “Recent advances in core analysis”, Petrophysics (2013), 54 (06), 554-579.

Subbey S., Monfared, H., Christie, M., Sambridge, M., "Quantifying uncertainty in flow functions derived from SCAL data” Transport in Porous Media, 2006, Vol. 65, pages 265-286.

Taber, J. J., "Dynamic and static forces required to remove a discontinuous oil phase from porous media containing both oil and water." Society of Petroleum Engineers Journal, March 1969, Vol. 9, pages 3-12.

Valvatne P. H., Piri M., Lopez X., Blunt M. J., "Predictive pore-scale modeling of single and multiphase flow", Transport in Porous Media (2005), 58, 23-41.

van Dijke M. I. J., Sorbie K. S., "Pore-scale network model for three-phase flow in mixed-wet porous media", Physical Review E (2002), 66, 046302.

Weitz, D. A., Stokes, J. P., Ball, R. C., Kushnick, A. P., "Dynamic capillary pressure in porous media" Physical Review Letters, 1987, Vol. 59, 2967-2970.

Table 1: Properties of individual core plugs and the composite core made for the coreflood experiments.

\begin{tabular}{|l|l|l|l|l|}
\hline Sample \# & Porosity, $\%$ & Permeability, $\mathrm{mD}$ & Length, cm & Pore Volume (He), cc \\
\hline Core-1 & 25.83 & 96.21 & 25.84 & 75.127 \\
\hline
\end{tabular}

Table 2: Compositions of the brine used in coreflood experiments.

\begin{tabular}{|l|l|}
\hline Ions & Composition (ppm) \\
\hline $\mathrm{Na}^{+}$ & 59491 \\
\hline $\mathrm{Ca}^{++}$ & 19040 \\
\hline $\mathrm{Mg}^{++}$ & 2439 \\
\hline $\mathrm{SO}_{4}^{--}$ & 350 \\
\hline $\mathrm{Cl}^{-}$ & 132060 \\
\hline $\mathrm{HCO}_{3}^{-}$ & 354 \\
\hline $\mathrm{TDS}^{-}$ & 213749 \\
\hline
\end{tabular}

Table 3: Properties of the fluids used in coreflood experiment

\begin{tabular}{|l|l|l|}
\hline Properties & Live Water & Live Oil \\
\hline Viscosity (cP) & 0.350 & 0.83 \\
\hline Formation volume factor & 1.01 & 1.30 \\
\hline
\end{tabular}




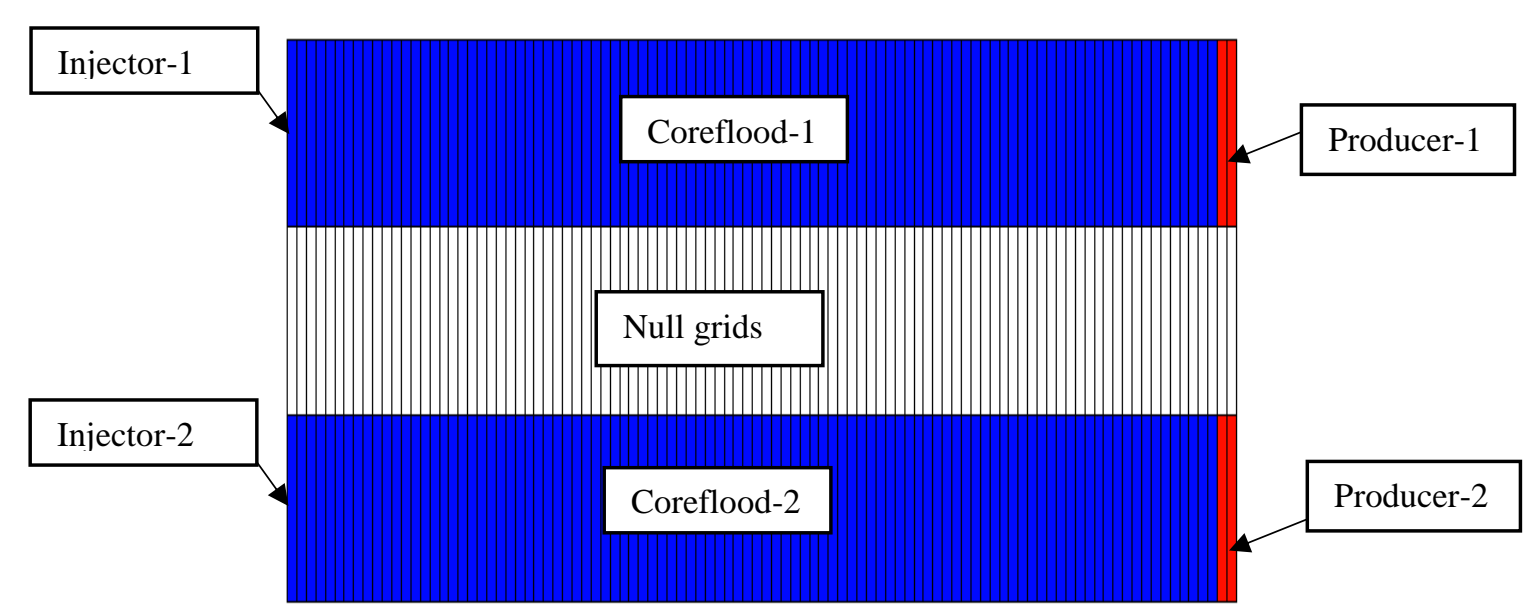

Figure 1: Sector model with three layers to represent two coreflood experiments together for co-history-matching. The upper and bottom layers are active cells to simulate corefloods whereas, the middle layer is assigned as null blocks. Two grid blocks at the end of core has zero Pc to simulate end-effects.

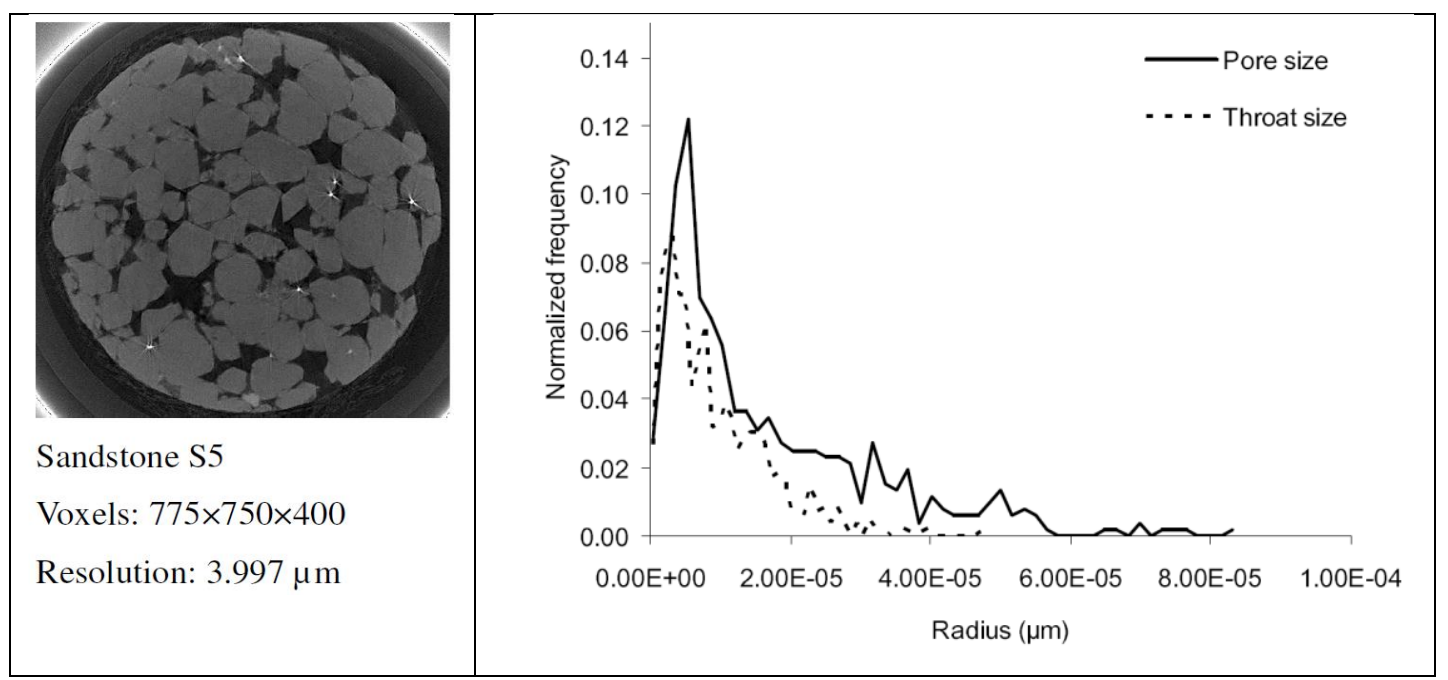

Figure 2: On the left hand side, Sandstone-S5 network extracted from pore-scale images (Fig 2a) and on the right hand side, the extracted pore and throat size distributions can be found (Fig $2 \mathrm{~b}$ ).

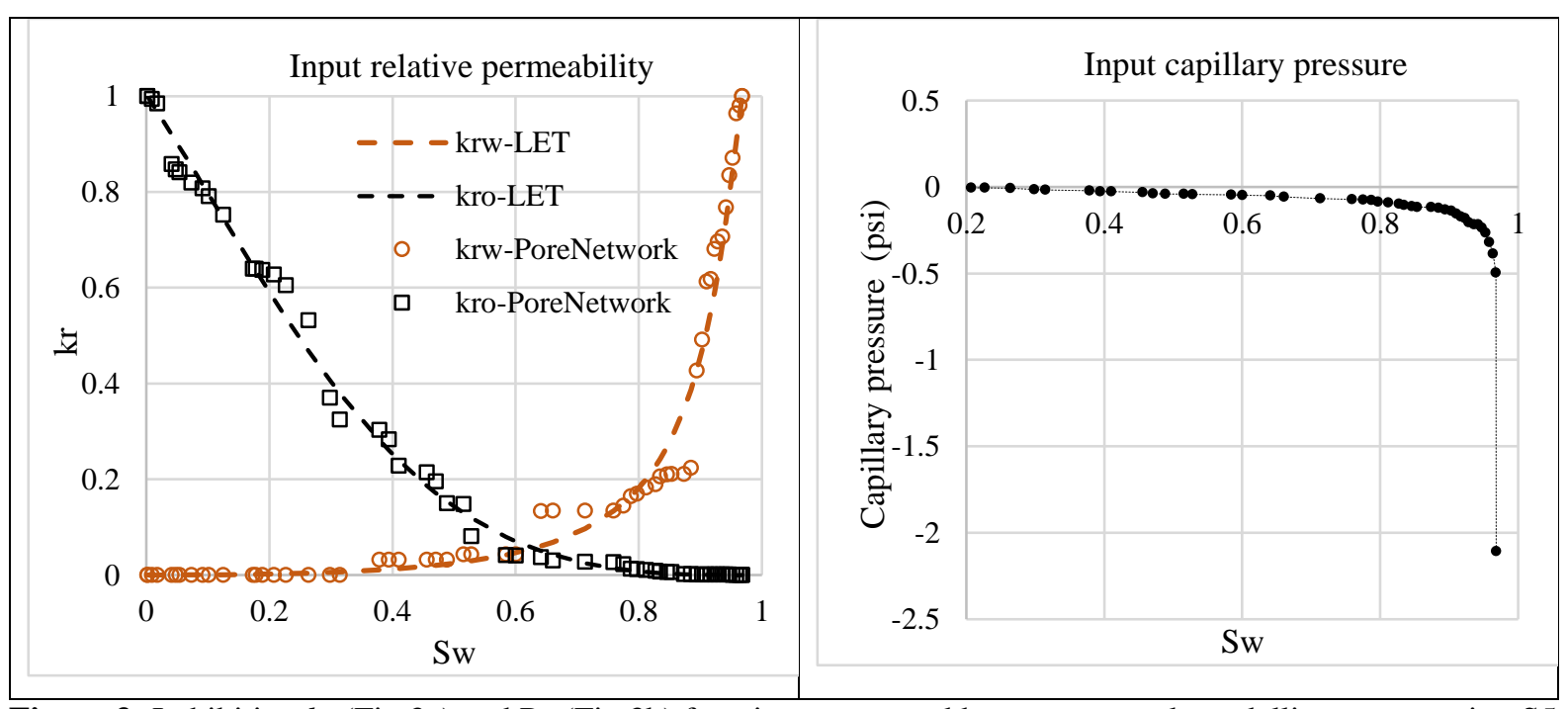

Figure 3: Imbibition $k r$ (Fig 3a) and Pc (Fig 3b) functions generated by pore network modelling representing S5 network data. Fig 3a shows relative permeability data with the smoothed curves fitted LET functions. 

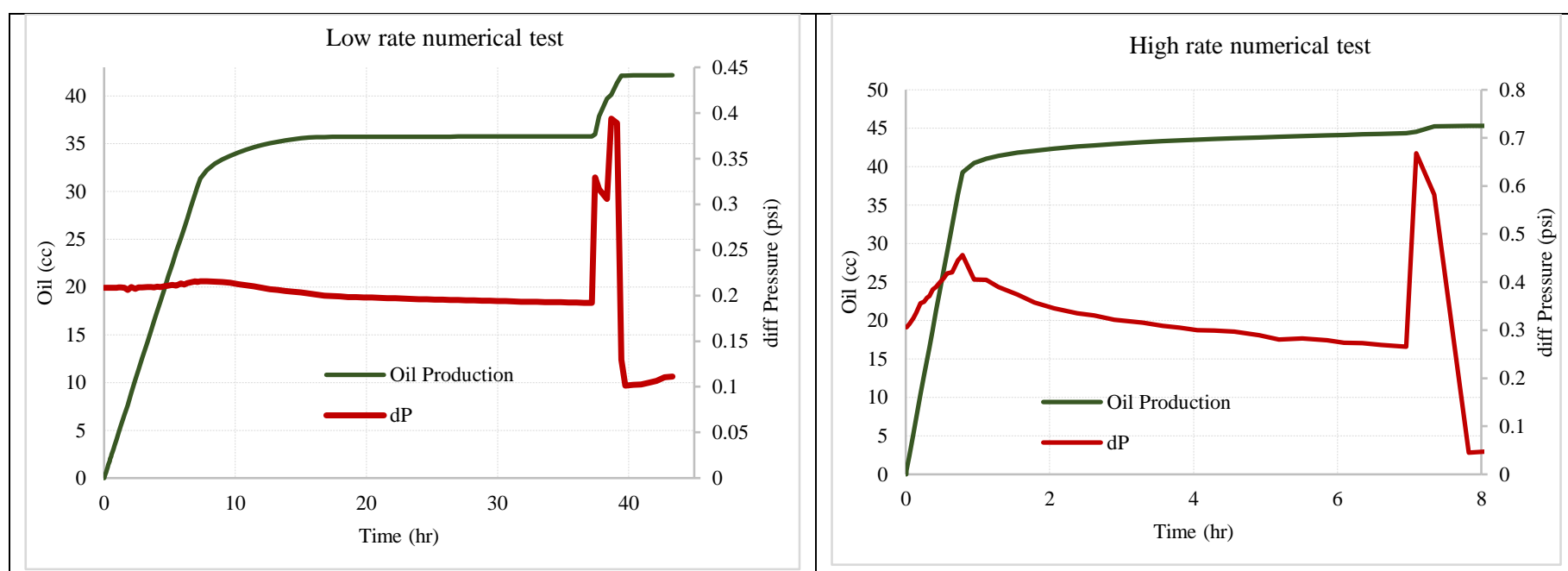

Figure 4: Oil Recovery and differential pressure data generated with coreflood simulator (CMG) using properties obtained from pore-network model of sandstone-S5 information. Fig 4a is for high rate numerical experiment whereas Fig 4b shows the low rate followed by bump flood periods.

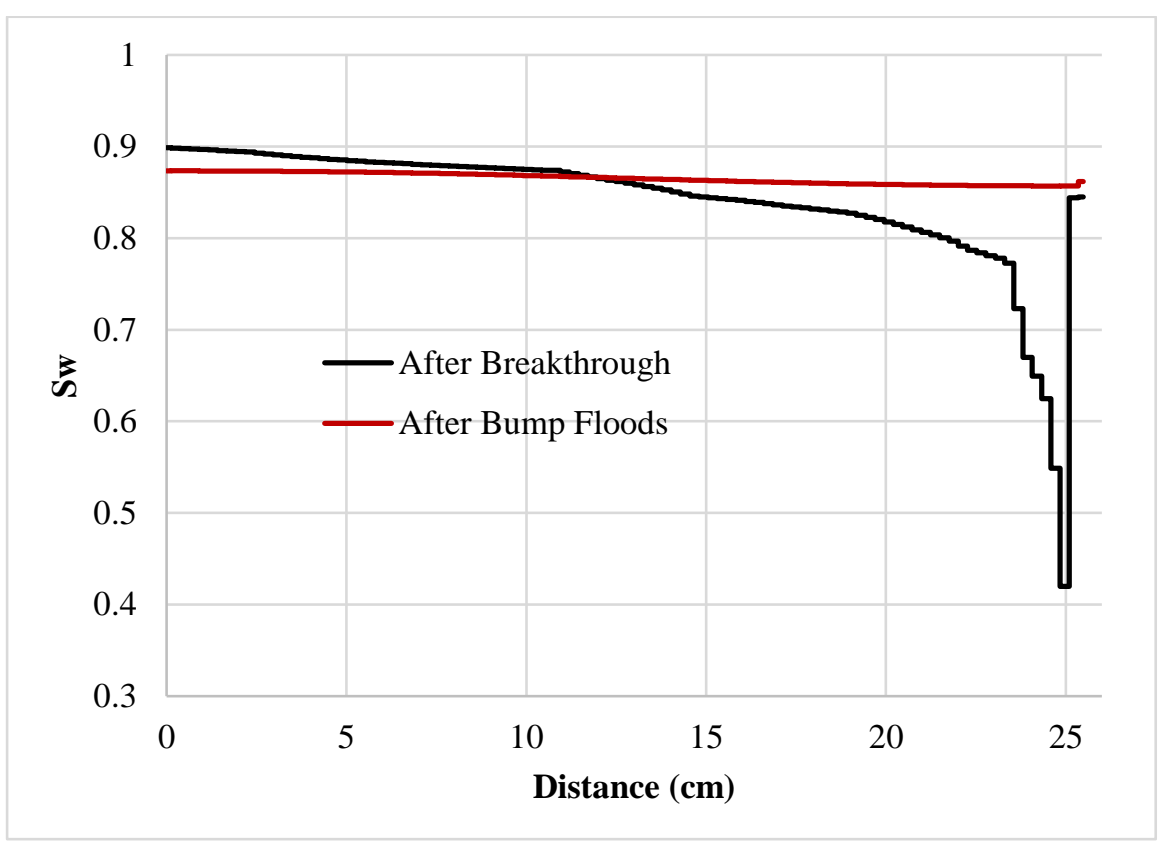

Figure 5: Water saturation distribution along the core form low rate experiment at two simulation times; after breakthrough and after bump floods. 


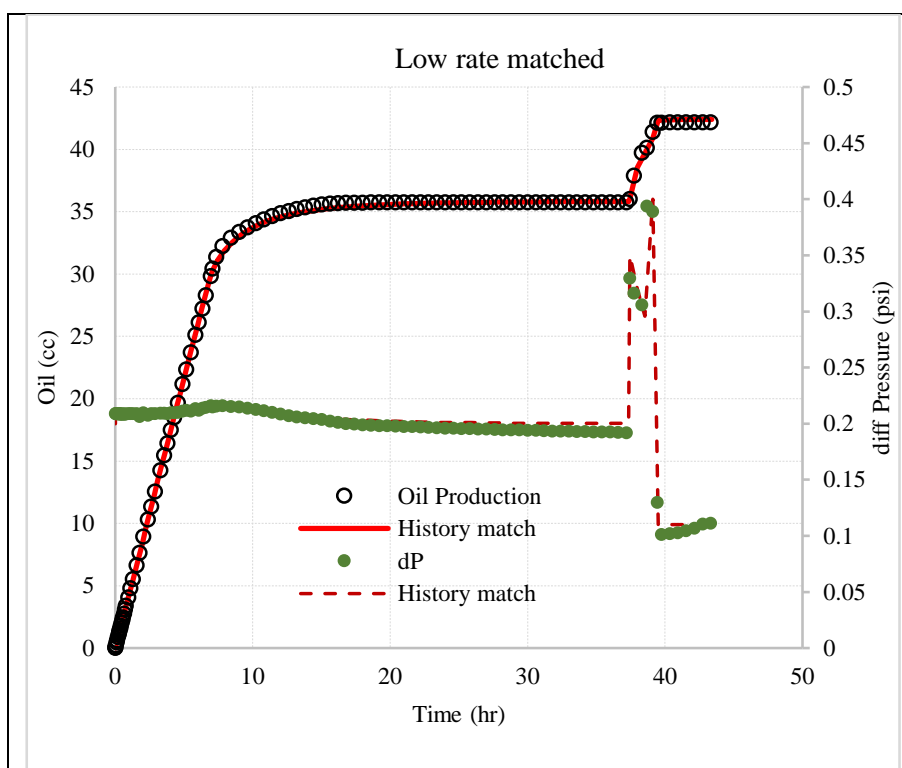

History-Matched

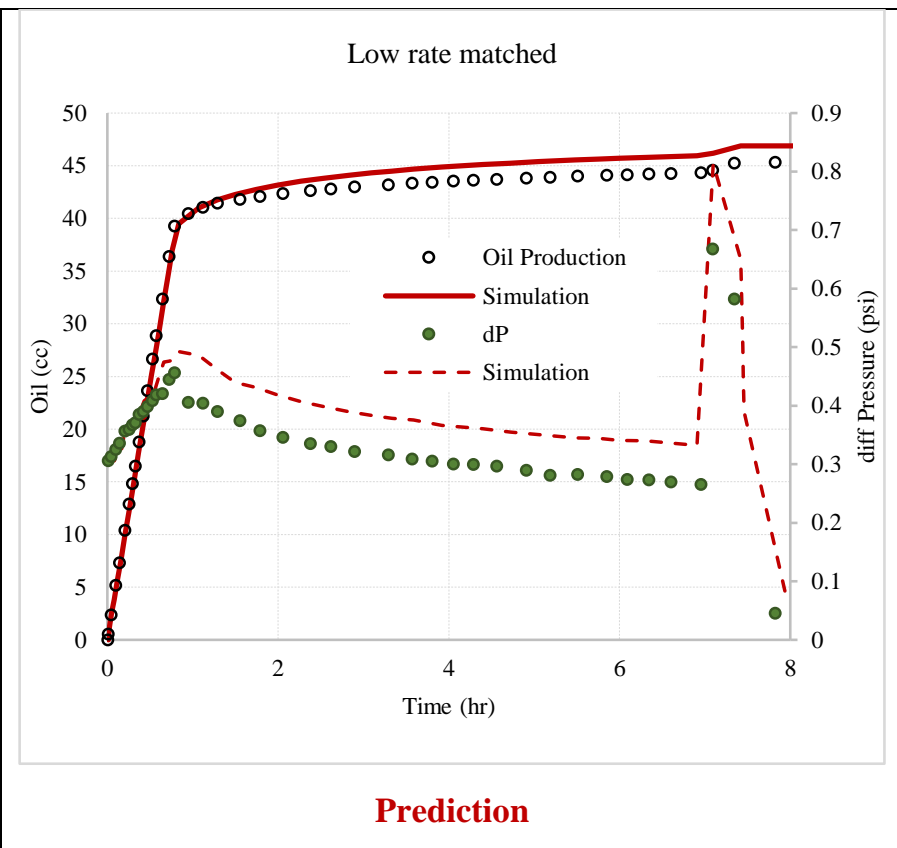

Figure 6: Oil Recovery and differential pressure profiles obtained by history matching of low rate experiment (Fig 6a) and forward simulation of high rate experiment (Fig 6b). The prediction of high rate experiment was a mismatch to experimental data. Green and blue dot points represent dP and oil recovery, respectively, for experimental data and red lines show simulation results.

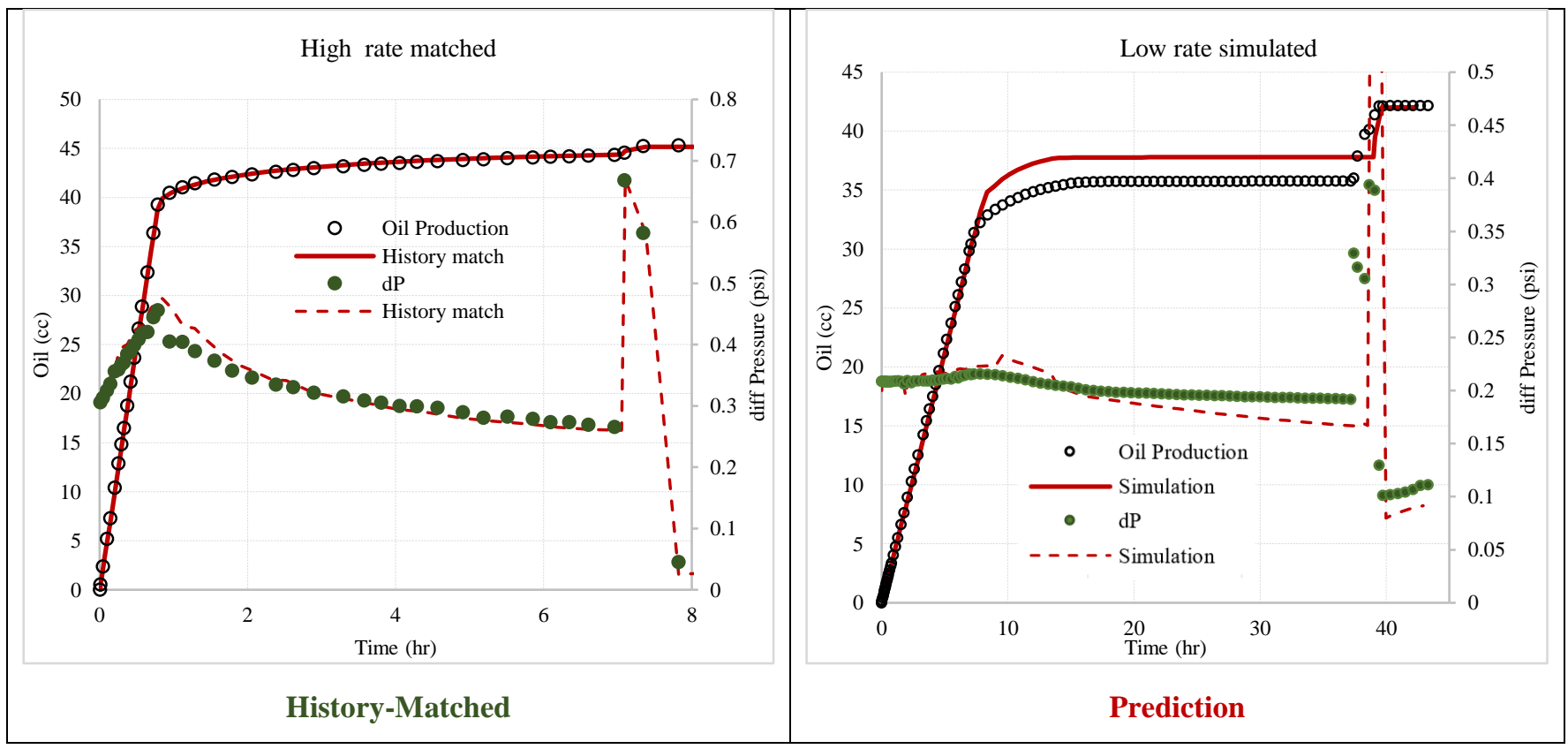

Figure 7: Oil Recovery and differential pressure profiles obtained by history matching of high rate experiment (Fig 7a) and forward simulation of low rate experiment (Fig 7b). The prediction of low rate experiment was a mismatch to experimental data. Green and blue dot points represent $\mathrm{dP}$ and oil recovery, respectively, for experimental data and red lines show simulation results. 


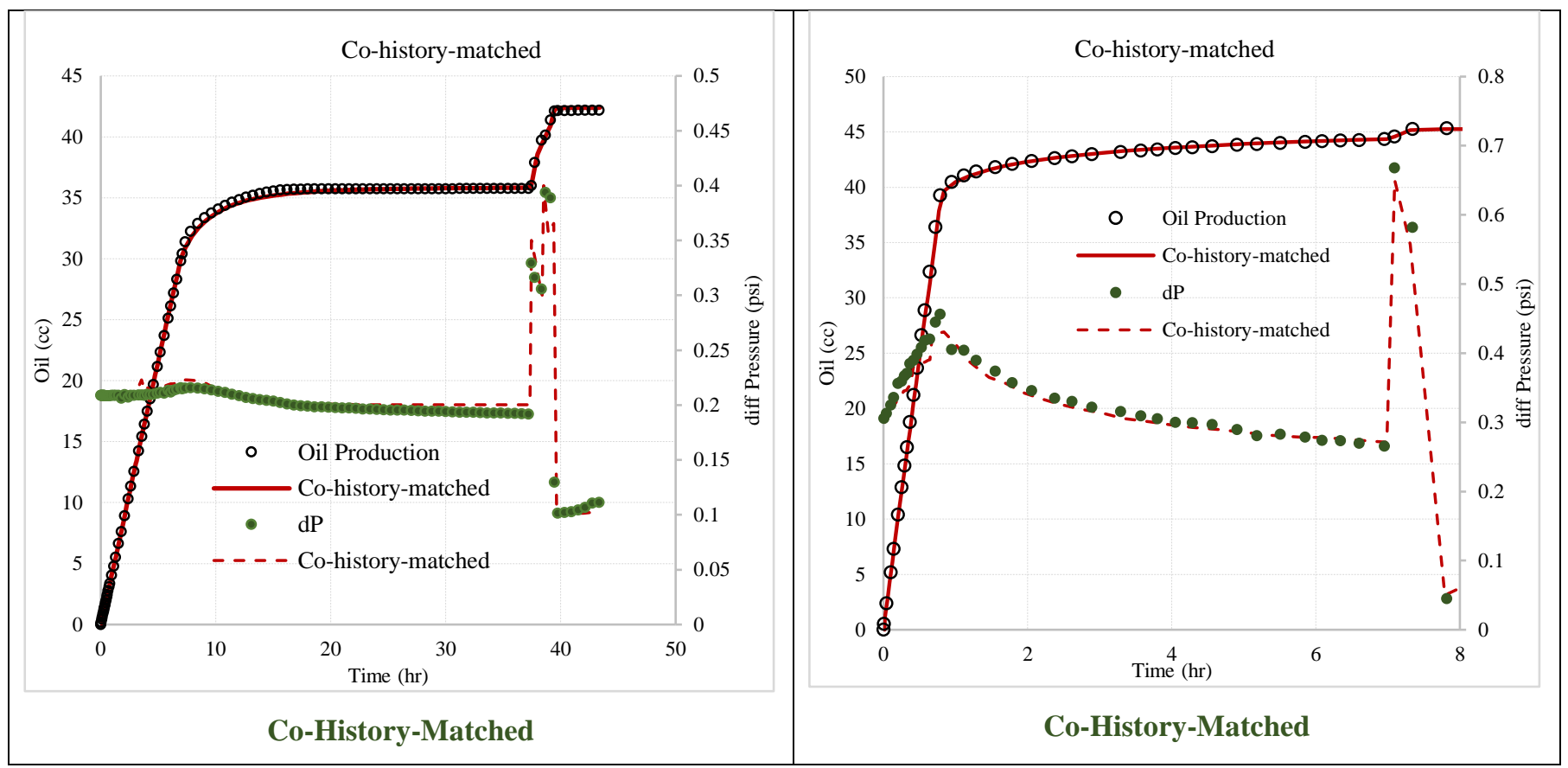

Figure 8: Oil Recovery and differential pressure profiles obtained by co-history-matching of both experiments together for high rate experiment (Fig 8a) and low rate experiment (Fig 8b). Acceptable match can be observed for both experiments. Blue dot points represent $\mathrm{dP}$ and oil recovery for experimental data and red lines show simulation results.

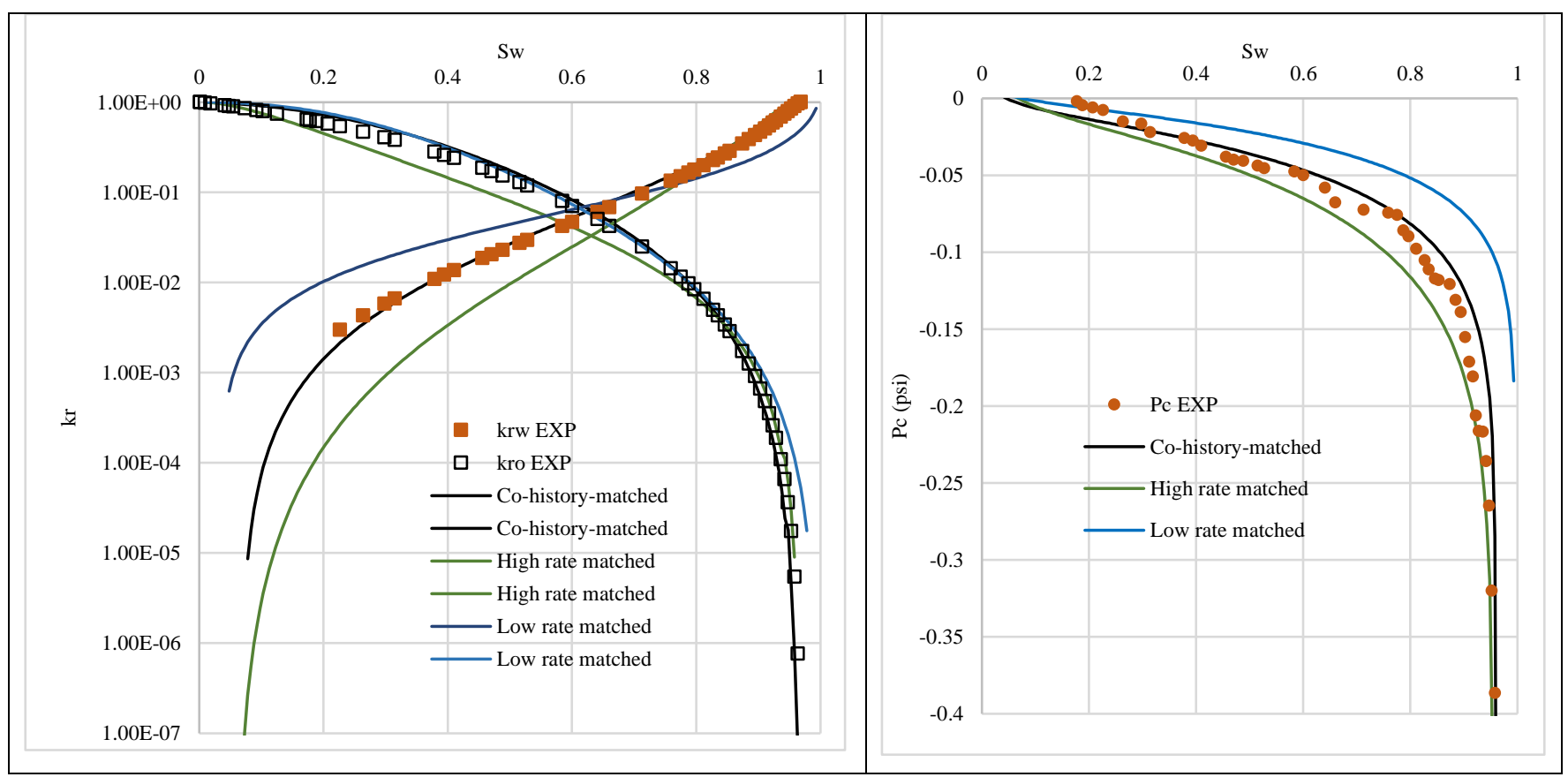

Figure 9: Relative permeability (Fig 9a) and capillary pressure (Fig 9b) functions from four sources, i.e. numerical experiment, co-history-matched, history matching of high rate, history matching of low rate cases. $k r$ and $P c$ curves obtained from co-history-matching show an acceptable degree of similarities compared to experimental data (pore-network) in the saturation range pertinent to unsteady-state coreflood, i.e. water saturation of 0.4-0.95. 


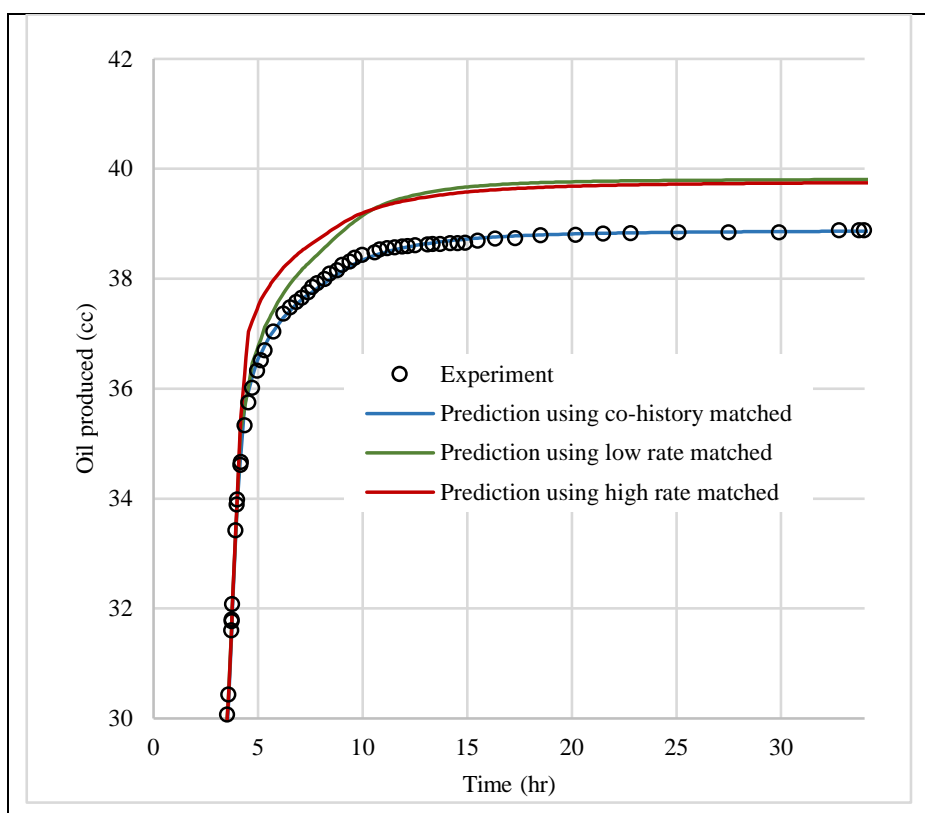

Prediction

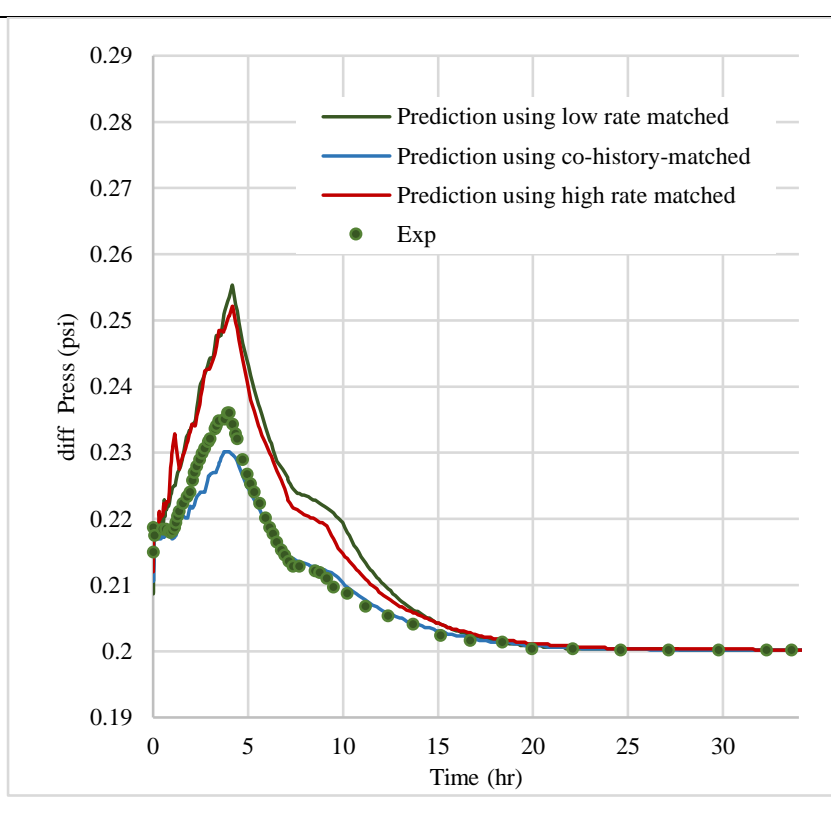

Prediction

Figure 10: Oil Recovery (Fig 10a) and differential pressure (Fig 10b) profiles obtained from forward simulation of the numerical coreflood performed at rate of $10 \frac{\mathrm{cm}^{3}}{\mathrm{hr}}$. Black dots are experimental data. Blue curves were obtained from tuned $k r$ and $P c$ of co-history-matching. Green lines were simulated by $\mathrm{kr}$ and $\mathrm{Pc}$ of low rate history matching. Red curves represent simulation results when $k r$ and $P c$ of high rate history matched case.

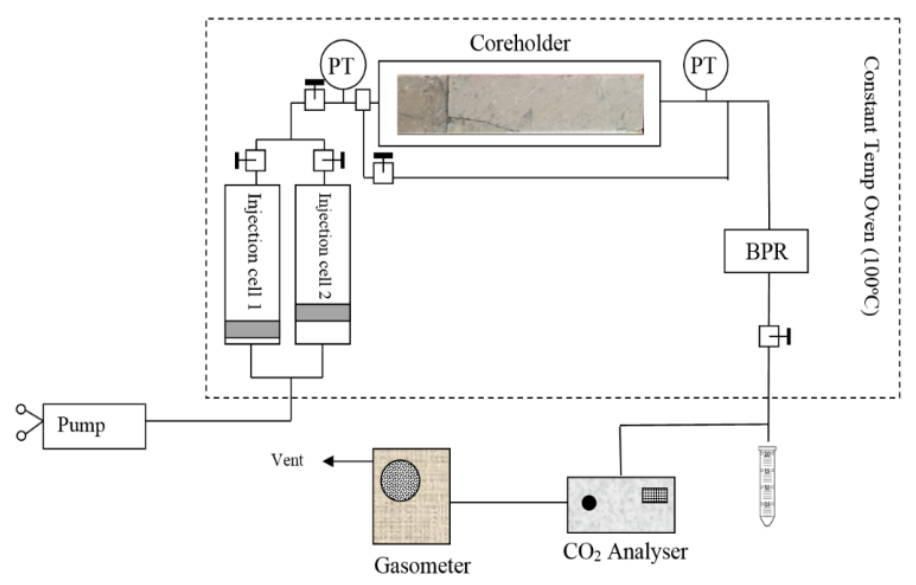

Figure 11: Simplified schematic of the experimental setup used for the core flood experiments. 


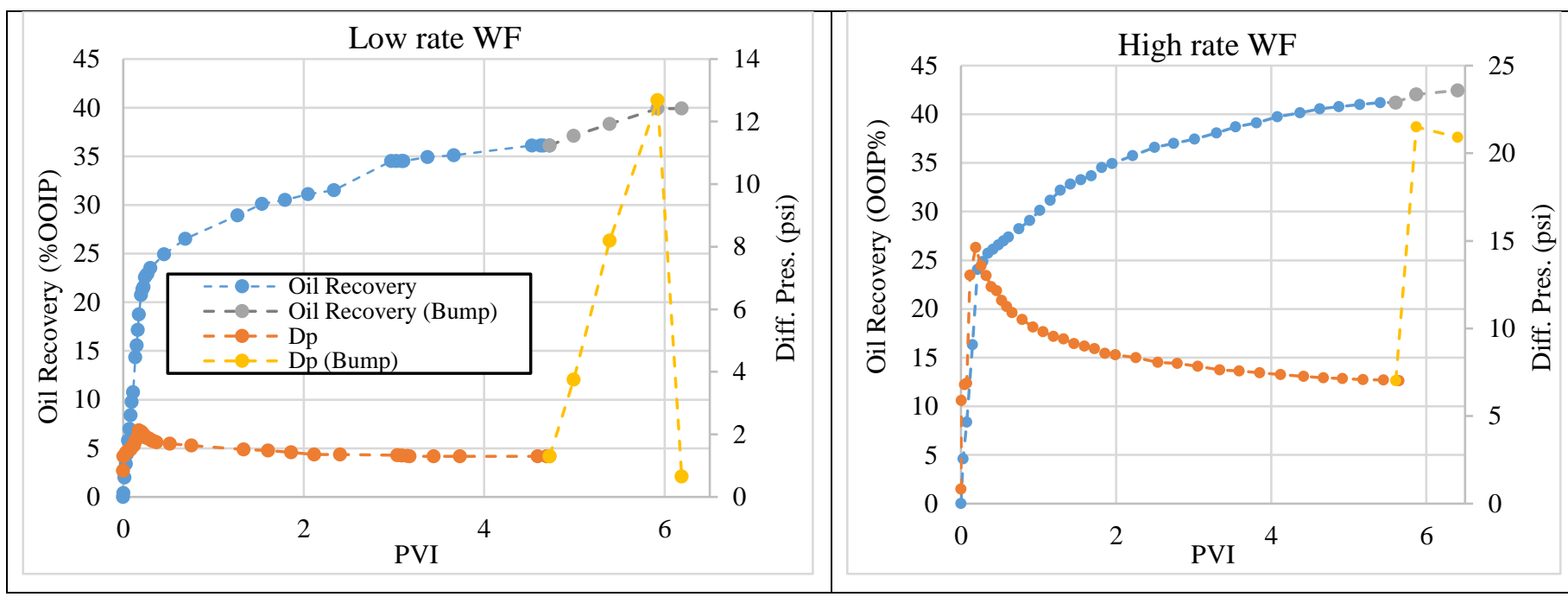

Figure 12: Profiles of oil production and differential pressure during water injection followed by a sequential bump flood. Fig 12a shows low rate coreflood experiment whereas, Fig 12b depicts high rate coreflood test.

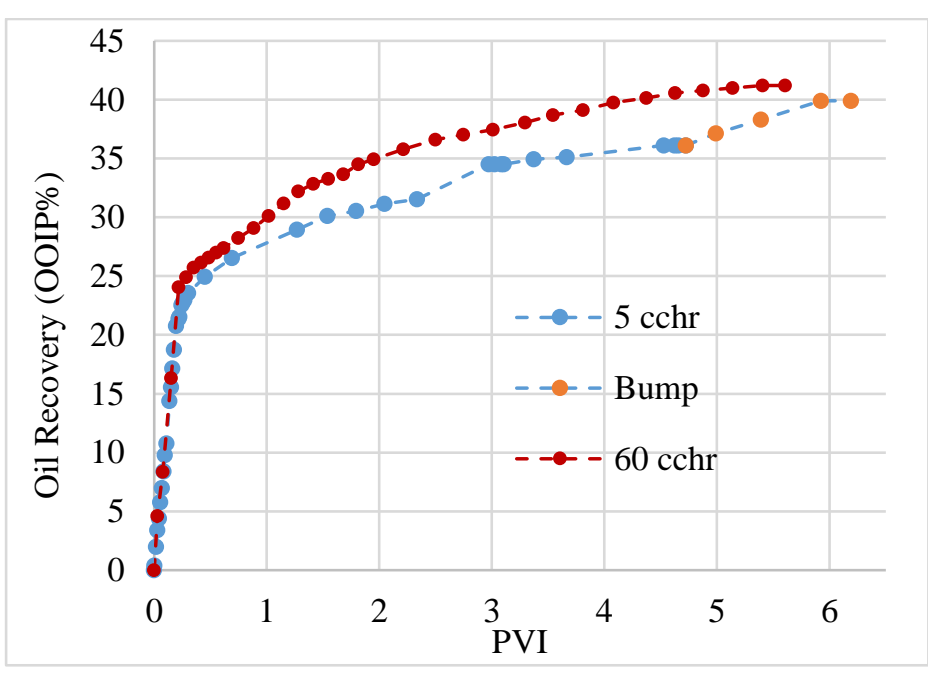

Figure 13: Oil production profiles in water injection experiments at two different rates, i.e. 5 and $60 \frac{\mathrm{cm}^{3}}{\mathrm{hr}}$. The ultimate oil recovery in both cases are almost exactly the same (41\% in high rate versus $40 \%$ in low rate + bump flood). The breakthrough occurred almost the same. 


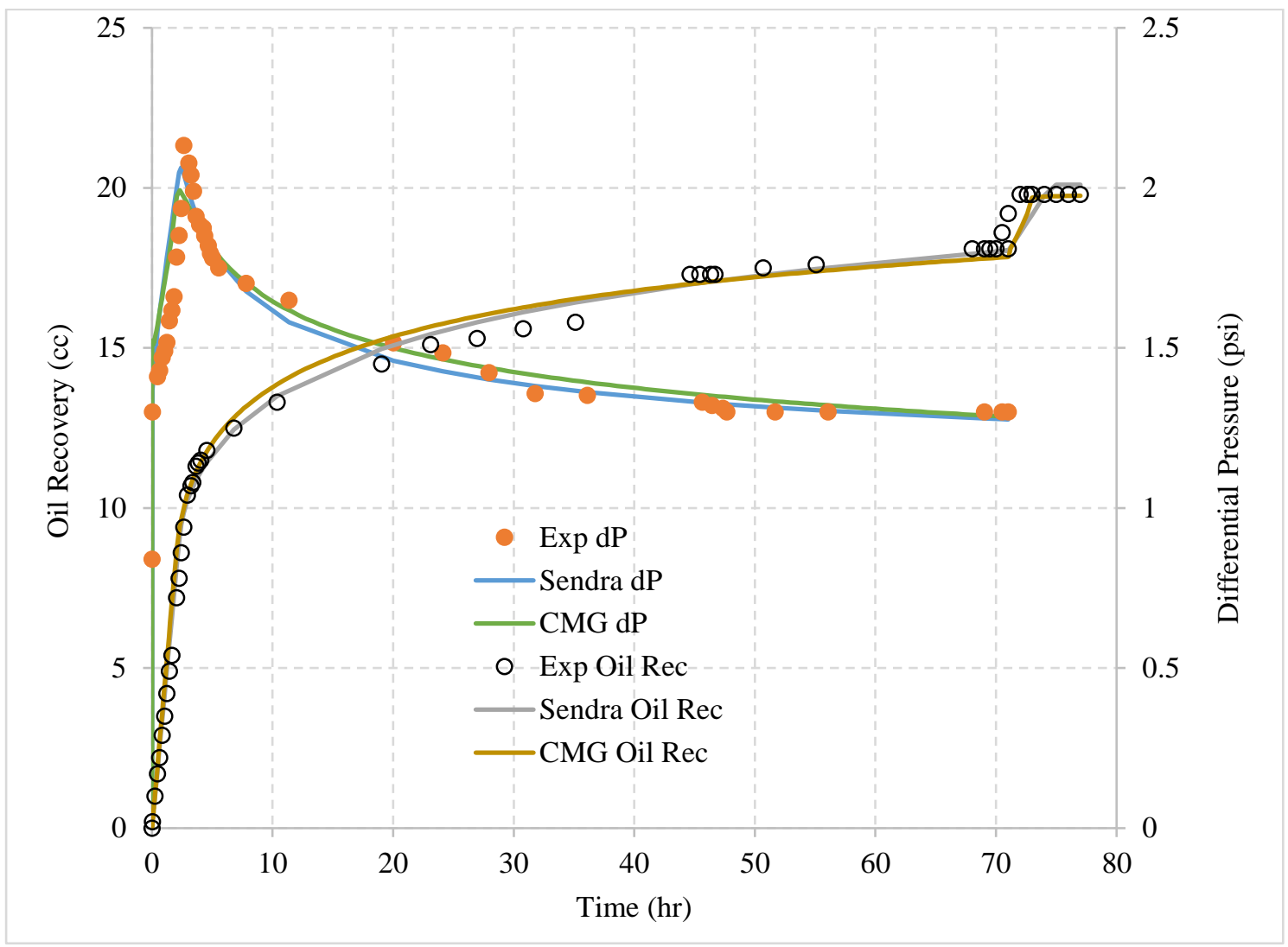

Figure 14: Results of history matching the waterflood sequences (low rate plus bump floods) plotted against the experimental data.

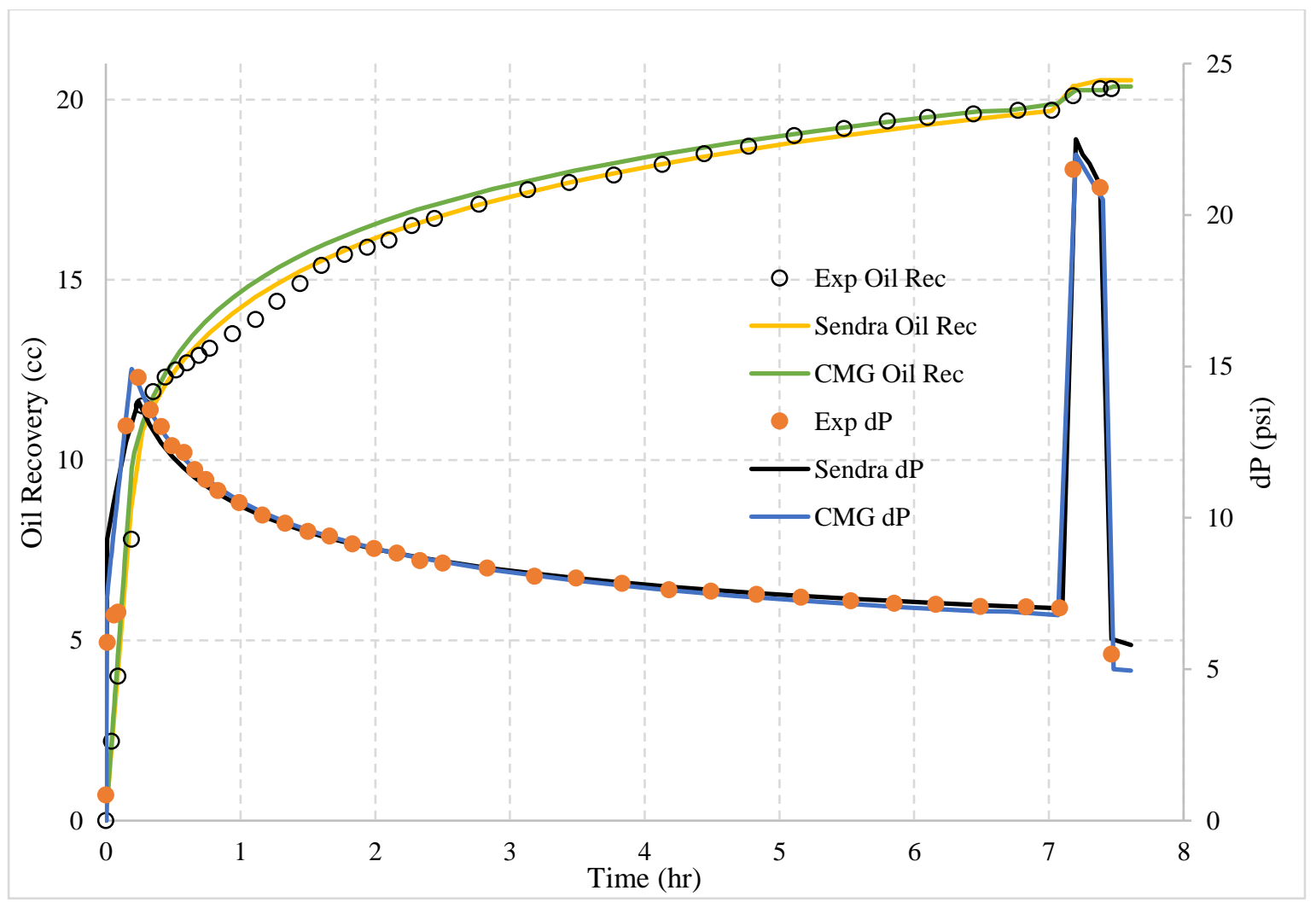

Figure 15: Results of history matching the waterflood sequence (high rate plus bump flood) plotted against the experimental data. 


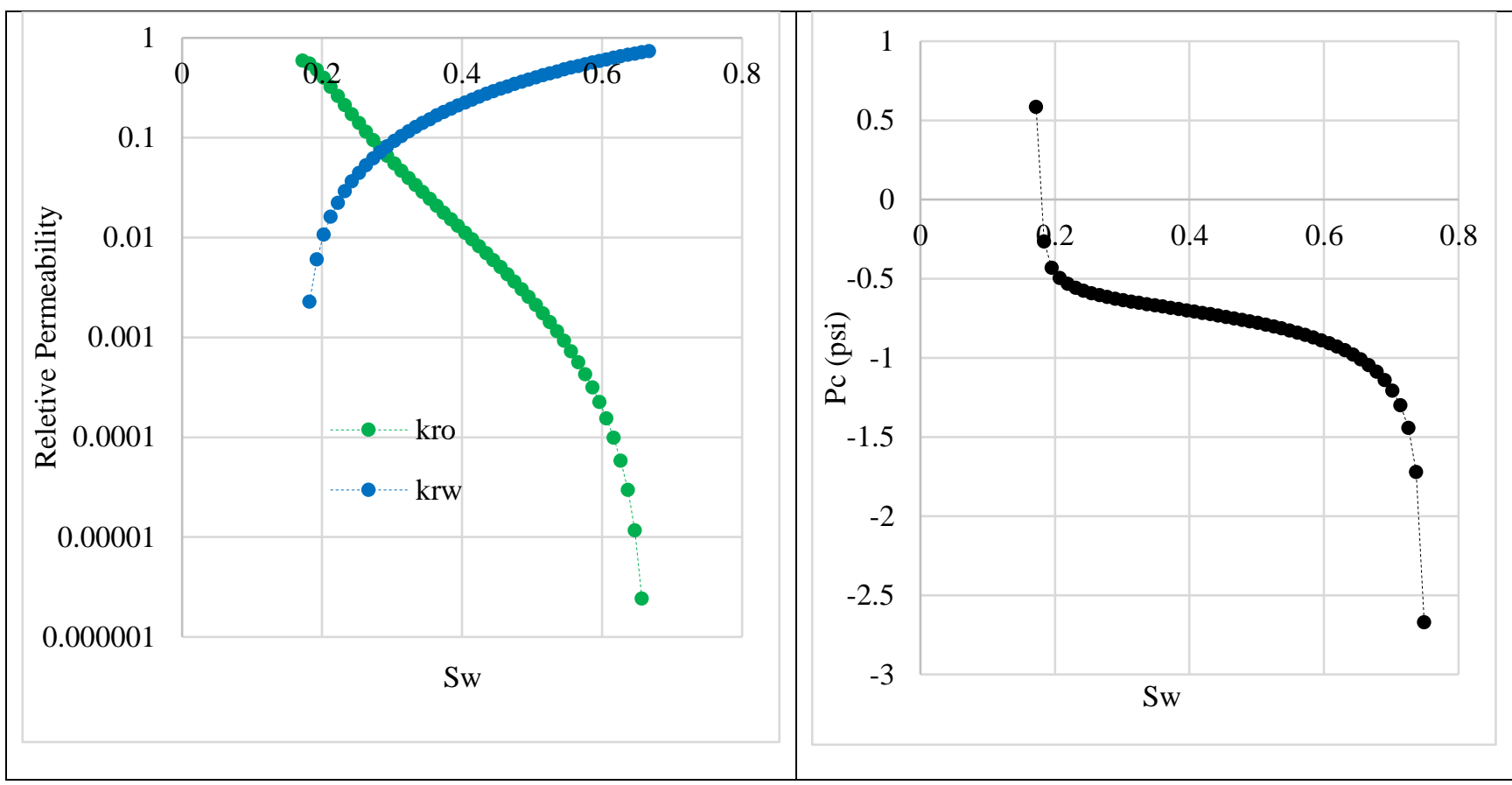

Figure 16: In semi logarithmic scale, relative permeability curves tuned on the coreflood experiment (Fig 16a). On the right-hand side (Fig 16b), tuned capillary pressure curve estimated from co-history-matching. 